Int. J. Dev. Biol. 53: 653-658 (2009)

doi: $10.1387 / \mathrm{ijdb} .082594 \mathrm{cc}$

\title{
Pattern formation today
}

\author{
CHENG-MING CHUONG*,1 and MICHAEL K. RICHARDSON ${ }^{2}$ \\ ${ }^{1}$ Department of Pathology, University of Southern California, Los Angeles, USA and \\ ${ }^{2}$ Department of Integrative Zoology, Institute of Biology, Leiden University, The Netherlands
}

\begin{abstract}
Patterns are orders embedded in randomness. They may appear as spatial arrangements or temporal series, and the elements may appear identical or with variations. Patterns exist in the physical world as well as in living systems. In the biological world, patterns can range from simple to complex, forming the basic building blocks of life. The process which generates this ordering in the biological world was termed pattern formation. Since Wolpert promoted this concept four decades ago, scientists from molecular biology, developmental biology, stem cell biology, tissue engineering, theoretical modeling and other disciplines have made remarkable progress towards understanding its mechanisms. It is time to review and re-integrate our understanding. Here, we explore the origin of pattern formation, how the genetic code is translated into biological form, and how complex phenotypes are selected over evolutionary time. We present four topics: Principles, Evolution, Development, and Stem Cells and Regeneration. We have interviewed several leaders in the field to gain insight into how their research and the field of pattern formation have shaped each other. We have learned that both molecular process and physico-chemical principles are important for biological pattern formation. New understanding will emerge through integration of the analytical approach of molecular-genetic manipulation and the systemic approach of model simulation. We regret that we could not include every major investigator in the field, but hope that this Special Issue of the Int. J. Dev. Biol. represents a sample of our knowledge of pattern formation today, which will help to stimulate more research on this fundamental process.
\end{abstract}

KEY WORDS: development, evolution, Evo-Devo, systems biology, morphogenesis, pattern formation

When we see patterns in peacock feathers (Fig. 1), leopard spots (Murray, 2003; Liu et al., 2006), or zebra stripes, we are fascinated by the order, the variations and the beauty. The biological processes that generate this ordering are pattern formation, a term popularized by Wolpert to describe the spatial organization of cell differentiation (Wolpert, 1969, and interview of Wolpert in Richardson, 2009a). Indeed, the processes of pattern formation can occur in the physical world as well as in living systems (Kauffman, 1993; Ball, 1999). Thus, we can also appreciate patterns in water waves, rock layers, and sand dunes (Fig. 2, Hazen, 2009), which emerge from apparent chaos or randomness. In living organisms, we can see patterns at different hierarchical levels, from molecular pathways, genome organization, developmental interactions, tissues, organs, body plans, and also at the level of animal behaviors. While the possibility of disorganization and disintegration is always present, organized patterns are able to emerge, and become stable, in many different systems and contexts. The formation of patterns is one of the key proper- ties of life.

What is the origin of the pattern-organizing ability of living systems? How is the information stored and retrieved? Here we will focus on how the one-dimensional genetic code is translated into multi-dimensional biological patterns, which may include both temporal and spatial components. We examine how diverse patterned phenotypes are generated in individual ontogenies and selected over evolutionary time. Some theoretical models have attributed the building of complex patterns to direct molecular coding - as though a blueprint for each part of the pattern is directly present in the genome. While this may be true in some primitive organisms,. this does not appear to be sufficient to explain the enormous complexity and variability observed in many biological patterns. Rather, it seems that many biological patterns may be built according to sets of rules, dictated by the

Abbreviations used in this paper: Abr, Abbreviation; Abrs, Abbreviations.

\footnotetext{
*Address correspondence to: Cheng Ming Chuong. Department of Pathology, Univ. Southern California, Los Angeles, USA. e-mail: cmchuong@usc.edu
}

Published online: 8 June 2009.

ISSN: Online 1696-3547, Print 0214-6282

(C) 2009 UBC Press

Printed in Spain 
genetic and physical-chemical properties of the system. Further, a large spectrum of complexity can be generated via informationefficient mechanisms such as through a combination (e.g., Liu et al., 2006) or co-optive use of these patterning-processes at different stages of morphogenesis, in different organs, or different species.

Molecular developmental biologists have made tremendous progress in identifying morphogens and signaling pathways (summarized in Wolpert et al., 2006; Davidson and Erwin, 2006). In recent decades, numerous loss- and gain-of-function experiments have demonstrated the critical role of certain molecules by showing that phenotypic changes are produced when a certain molecule is misexpressed or inactivated. However, much less is known about how cells are integrated into tissues, and tissues into organs (Edelman, 1993; Chuong et al., 2006). At the other end of the research spectrum, some scientists have developed theoretical models, trying to explain and simulate the organizing behaviors of biological systems (Murray, 2003; Meinhardt and Gierer, 2000). While many of these models are elegant, more experiments are needed to evaluate them and bring out molecular basis of the parameters (Maini et al., 2006).

Some scientists have recognized these knowledge gaps, and have attempted an integrative line of thinking. Indeed, integrative and systemic studies that combine several different fields of expertise are gaining ground in mainstream research. The emerging field of evolutionary developmental biology ('Evo-Devo') is a good example of such integration: it requires knowledge of phylogeny, paleontology, anatomy, genomics, molecular biology and development. Now, more than ever, we think the time is ripe to accelerate the integration of this research. For example, beyond molecular interactions, cells may communicate based on physical-chemical properties of whole cells or cell clusters (Christley et al., 2007). At the level of tissue interactions, cells are affected by the mechanical properties and molecular gradients in the micro-environment, but can also modify their environments through feedback loops. Furthermore, cells might oscillate through competent and non-competent states of certain functions (as in the 'molecular clock' involved in somite formation; Dequéant et al., 2006). The combinations of these interactions produce a variety of organized structures: stripes and dots (Baker et al., 2009), branching patterns, traversing waves (Kondo et al., 2009; Plikus et al., 2008, 2009), etc. The principles and rules appear to be similar at the core of different patterning processes in different organs - and also - in different species. It is recognized that patterning mechanisms may be conserved between phyla. They are manifested differently at different organization levels, and the modulation of these processes can even lead to the generation of evolutionary novelties.

Another key, but often neglected, component of patterning mechanisms is the control of timing. The temporal order of gene expression may have profound influences on patterning, as is known for the temporal colinearity of Hox genes, for example (Duboule, 1994; and interview of Duboule in Richardson, 2009b). In evolution, timing differences in patterning systems (heterochrony) may underlie phenotypic differences, as may be the case with beak shape in Darwin's finches (see Abzhanov et al., 2004; Wu etal., 2004; and interview of Cliff Tabin in Richardson, 2009c). The study of Hoxgene organization at the genomic level provides novel information about the regulation of clustered developmental

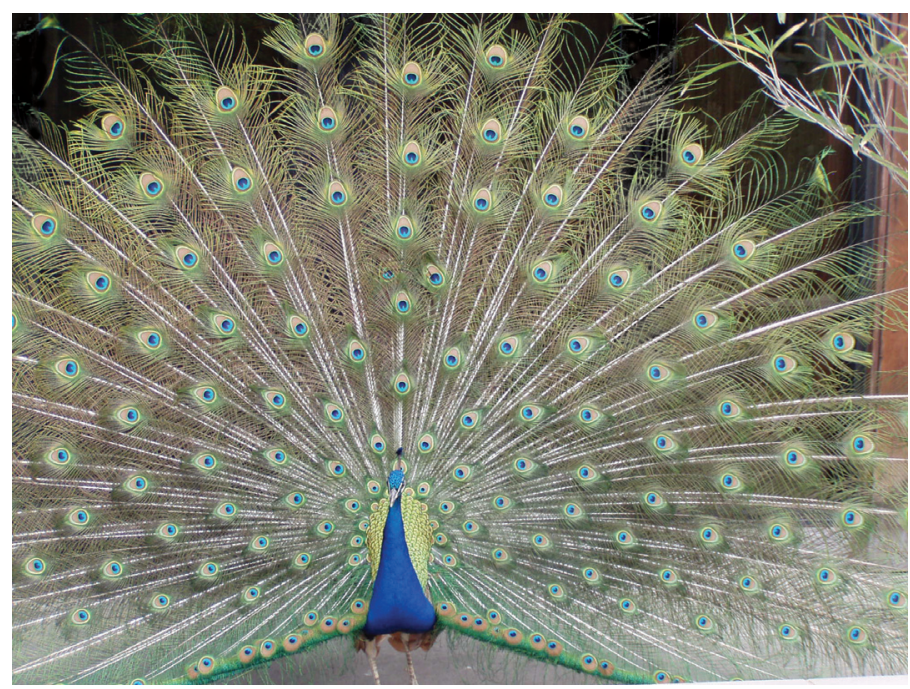

Fig. 1. Peacock plumage as an example of biological pattern formation. The complex pattern is produced by a combination of the arrangement of feathers, differential regulation of feather length, shapes of the feather vane, texture of the feather barbs (producing optical interference patterns), and the differentiation of neural crest cells. Indian Blue Peacock (Pavo cristatus) in Los Angles Arboretum in March, 2008. Photo by Cheng Ming Chuong.

genes which is critical for our ability to modulate the progression of stem cells (Kmita et al., 2000).

Many scientists have noticed that there is an obvious connection between pattern formation, regeneration and, by extension, tissue engineering. In these fields, knowledge of pattern formation mechanisms could help us learn how to build organized tissues from a population of homogeneous stem cells. We strongly believe that tissue engineering (the creation of artificial tissues from a patient's own cells) is a field that will benefit greatly from the application of knowledge that has been gleaned from pattern formation (Brockes and Kumar, 2005; and interview of Susan Bryant in Richardson and Chuong, 2009).

In the current research funding climate, biologists are also encouraged to find medical applications for their work. In addition to being fundamental to biological processes, research into pattern formation do indeed have such applications (See Brittijn et al., 2009). An understanding of the process of developmental patterning can help us identify the causes and potential management of human congenital malformations and potential management. It also helps us learn how to build organized patterns from a population of homogeneous stem cells. The study of patterning genes has shown many examples of genes that also have a role in disease. The involvement of Hoxgenes in some leukemia is a good example.

The purpose of this Special Issue is to catalyze a new synthesis in this field and to focus more attention on the gaps between molecular biology and simulated models of organized biological patterns. We wish to learn more about the principles of biological organization. What is a 'pattern'? Can it be defined by regular, repeating units? How robust are patterning mechanisms: in other words, how much disruption can they tolerate before patterns disintegrate? How does biological pattern formation achieve so much more complexity than pattern formation in the 
non-living world? How much precision do patterning mechanisms show, as measured by how many phenotypic discontinuities they can accurately specify? How much can we attribute the organized pattern to molecular coding, and how much to information-efficient mechanisms using a few simple rules and mechanisms? How much can we ascribe the property of self-organization to patterns, and how important are epigenetic factors? If molecules do not directly encode patterns, how many levels of information processing are there between molecular codes and the emergent final pattern? How much self-organizing behavior can we predict and how much is a function of probability? At a higher level of organization, how is specificity maintained despite some loss of precision? Can we highlight these principles and uncover their molecular basis? How are the parameters involved in these processes modified by natural selection? We organize these topics under the themes of 'Principles', 'Evolution', 'Development', and 'Stem cells and Regeneration'.

\section{Principles}

Pattern formation is such a wonderful phenomenon that biologists sometimes think patterning is unique to the living system. But fantastic patterns can also emerge in non-living systems. We purposely started with a discussion of pattern formation in a nonliving system by Drs. Epstein and Vanag, who are theoretical chemists (Vanag and Epstein, 2009). Here we can see how form can be generated, and can progress dynamically and cyclically, as a result of physical-chemical process. The extraordinary feature of this system is that different theoretical models can be tested experimentally by altering each chemical parameter. We then consider how the 'order', in different hierarchical levels may lay down the foundation for the origin of life. Dr. Hazen, who has a background in geology, starts by discussing patterns in the physical world: sand dunes, river valleys, rock layers, the beautiful landscape that unfolds beneath us when we fly from one meeting to the other. He discusses how 'agents', living or nonliving, can interact to form various patterns, and how the hierarchical ordering of this process can be used to build complex patterns. He also illustrates how functional information generated this way may be the basis for the emergence of life (Hazen, 2009), and uses RNA molecules as a model in his discussion.

We interview Lewis Wolpert, and discuss his early theoretical work on positional information, and how this set the scene for a renaissance in studies of patterning (Richardson, 2009a). Wolpert describes how he worked on sea urchins and hydra, developing his French Flag model; and then applied his ideas to patterning of the chick limb. He describes how the concept of 'morphogens' a term coined by Alan Turing (Turing, 1952) - was adopted by Francis Crick as a mechanism for developmental gradients including positional information (Crick, 1970). Wolpert also explains why he now believes the morphogen gradients alone are no longer sufficient to explain the mechanism of positional information.

Patterns in biological system, simple and complex, can be very useful as a Rosetta stone - a key to decoding the conserved principles of pattern formation in evolution and development (Slack, 1984). To this end, Newman and Bhat (2009) have proposed a set of dynamical patterning modules which may work as 'pattern language'. This language may be used for communi- cation between cells when they form tissues and organs in development and in the formation of multicellular communities during evolution. We also interviewed Dr. Newman, and to see how he, coming from a chemical physics background, developed an interest in biological pattern formation (Chuong, 2009a). Starting from the limb bud model, he has provided fresh perspectives and developed a comprehensive framework for the role of physical mechanisms in morphogenesis. These views deserve more attention and tests from experimental biologists.

While epigenetic factors and stochastic events based on physical-chemical principles have roles in pattern formation, the information for biological patterning, directly or indirectly, still is based on molecular properties and begins with genetic information (Jiang et al., 2004). Peters and Davidson (2009) use this assumption in their elucidation of the genomic control of pattern formation. They use the formation of sea urchin endomesoderm as a vivid example to illustrate how sequential and hierarchical interactions of cis-regulatory elements can lead to patterning of tissue layers. They further propose how the interaction of gene regulatory networks or «kernels» of gene regulatory networks can lead to the emergence of many animal body plans in Cambrian period and the conservation of phyletic body plans (Davidson and Erwin, 2006). Their work also shows the emerging power and importance of genome-wide bioinformatics research.

\section{Evolution}

The sudden appearance of diverse animal body plans is vividly illustrated by fossils unearthed from Chengjiang Biota in Yunan, Chian, and which have their origin in the Cambrian period, 530 million years ago (Chen, 2009). It is particularly interesting to consider how these ancient animal body plans arise in the context of both Newman's "dynamical patterning modules" (Newman and Bhat, 2009), and Davidson's "gene regulatory networks" (Peters and Davidson, 2009). While the evolution of body plans and

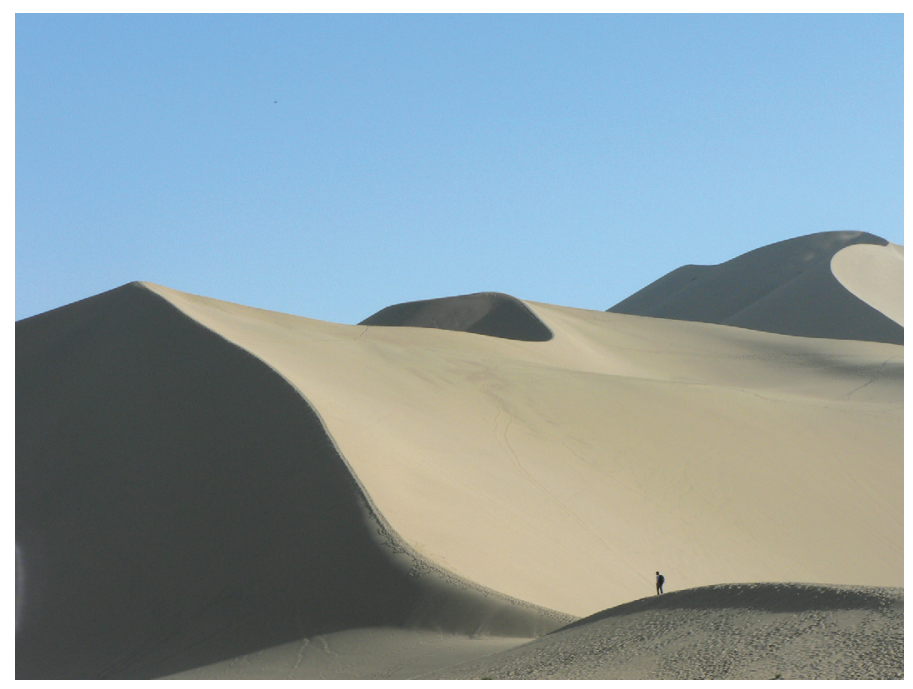

Fig. 2. Sand dune as an example of pattern formation in non-living systems. The property of sand grains, the wind and gravity work together to produce periodicity in sand ripples and sand dunes. See also Hazen (this issue). Sand dunes along the silk road, Dunhuang, China. Photo by Cheng Ming Chuong. 
phenotypes are based on natural selection, their survival is best served via adaptive cooperation among molecules, modules, organelles, cells, tissues, organs, etc. (Weiss and Buchanan, 2009). These authors apply their concepts to draw a comparison between evolution and development: most processes are in parallel, with difference being that competition is a key to successful evolution, while cooperation is a key to successful development.

Hoxgenes are among the most intensively studied genes in the context of pattern formation. We interview here Denis Duboule, a pioneer in the study of the murine Hoxgenes. Duboule describes how, over the last 10 years, his technique on targeted meiotic recombination has allowed spectacular advances in our understanding of Hox gene regulation and cluster organization (see interview of Duboule in Richardson, 2009b). The vertebrate Hox clusters have evolved through several rounds of cis-and transduplication. Axel Meyer considers here these genome duplications, and their implications for the evolution of morphology in different vertebrate groups. Meyer's work is an excellent example of how an integrative approach, based on biogeography, ecology, molecular developmental biology and genomics, can help us to understand the nature and mechanisms of evolutionary change (Kuraku and Meyer, 2009).

We interview Cliff Tabin who, like Duboule, pioneered the application of molecular biological techniques to the chick limb system, and made major advances in our understanding of the role of sonic hedgehog as a morphogen. Tabin is a truly integrative scientist working in the field of pattern formation, and his work ranges from the Evo-Devo of Darwin's finches to the genetic basis of cave fish evolution (Richardson, 2009c).

\section{Development}

Some of the most inspiring works on how patterns form in embryos were done with micro-surgery and recombinations in the classical era. This was best illustrated in the heterotypic, heterochronic, and xenospecific epithelial-mesenchymal recombination which revealed that patterns are controlled by the mesenchyme. Dr. Dhouaily is a scientist whose work transcends the classic and molecular era on feather pattern formation and stem cell plasticity. Here she shares us her perspective in an interview (Chuong, 2009b).

Current molecular approaches focus more on experimental phenotypes caused by gain- or loss- of function experiments. These analytical approaches have greatly advanced our understanding, and are proving even more powerful when they are integrated into a conceptual framework that allow us to build robust models of pattern formation. This is beautifully illustrated by Duboule's approach to Hox gene function, which has raised our understanding on patterning to a new level (Richardson, 2009b). Here Baker et al., (2009) presents mathematical models on how temporal waves and spatial patterning may work in somite segmentation and feather bud pattern formation. At the molecular level, Roignant and Treisman (2009) demonstrate elegantly how signaling genes in the morphogenesis tool kit, such as Hedgehog and Notch, are used to construct the exquisite patterns in the Drosophila eye disc.

Cheryll Tickle reviews concepts of pattern formation as applied to tetrapod limb development (Towers and Tickle, 2009). Tickle pioneered the experimental study of morphogen gradients in the chick limb using microcarrier beads, and famously discovered the polarising activity of retinoic acid, perhaps the first morphogen to be discovered in vertebrates. Through a series of brilliant experiments, she showed that retinoic acid and the polarising region (ZPA) shows morphogen properties such as 'attenuation' weakening of their effect on the phenotype at lower doses. Tickle shows the advantages of the chick limb system for studying pattern formation - in particular its accessibility to surgical manipulation at early stages.

We may consider that features such as appendage patterns are easier to modify in evolution than the Bauplan of the phylum. Gene regulatory networks specifiying the Bauplan are relatively impervious to evolutionary change. Modifications can produce large phenotypic changes, such as those that exist between phyla (Davidson and Erwin, 2006). Gene regulatory network for body appendages such as the limbs are not easy to modify, and varaiations mean changes from fishes to tetrapods. Changes in gene regulatory networks for integumentary appendages may not be subject to such strong selection because such appendages are numerous and dispensable. Furthermore, amniote integumentary appendages are specified relatively late in development, long after most other organs have already been laid down. Changes leading new integumentary appendages can evolve without causing widespread pleitotropic effects on the other organs. On the other hand, the consequence of evolutionary innovation in skin appendages can still be enormous. The feathers and hairs that evolved from reptilian scales indeed are the cardinal features of two new amniote classes, Aves and Mammalians respectively The values of the reptilian scale model in the pattern formation, evolution and regeneration of integumentary appendages is highlighted (Chang et al., 2009).

\section{Stem cells and regeneration}

Regeneration is the process whereby cells can reform their functional counterparts after tissue loss, in contrast to repair when cells can only fill in the tissue defect. One major issue is to understand how cells gain self-organizing patterning ability in regeneration, and how it is similar and different from developmental pattern formation. Dr. Susan Bryant has had a distinguished career in studying this process in amphibian limb and here we have interviewed her to explore her thoughts on these questions (Richardson and Chuong, 2009)

With the advent of stem cell biology and regenerative medicine, scientists seek to engineer stem cells into organized patterns (Chuong et al., 2006). The study of pattern formation is no longer just of academic interest, but has very practical ramifications. It is not sufficient simply to regard stem cells as sources of various differentiated cells types. This approach to tissue engineering, whereby stem cells are seeded onto artificial templates in the presence of differentiation factors, has very limited potential for growing artificial tissues. But by applying the principles of pattern formation, it should be possible to develop artificial tissues that, in effect, create their own template. Knowing how to get stems cells to organise themselves into specific topological configurations, as they do in the embryo, could be the 'new wave' of tissue engineering. Richardson's group discusses how zebrafish developmental biology can be exploited for applications such as tissue engineer- 
ing and biomedical screening assays (Brittijn et al., 2009). They show that the zebrafish model can, in principle, be used as a costefficient, high throughput screening assay, by exploiting and applying knowledge of pattern formation. Regeneration of the caudal fin in adult zebrafish is developed as a model in which regeneration can be modulated by chemicals implanted on micro-carrier beads. They argue that this system could be developed into a medicallyuseful screening assay.

Perhaps the best way to learn how to stimulate and control regeneration is to study organs in species which regenerate routinely and under physiological conditions. In these cases, the regeneration processes has been subject to selection over millions of years. In a sense, evolution has carried out a large scale genetic experiment on our behalf. The mammalian hairs (Stenn and Paus, 2001) and chicken feathers (Yue et al., 2005) are such regenerative organs. A hair follicle is considered as a mini-organ that goes through several regenerative cycles in the life time of an animal. An individual mammal typically has thousands of hair follicles on its skin. How the cycling of these hair follicles are coordinated (simultaneously, randomly, or in waves) has not been addressed before. By analyzing hair cycle domains, Plikus et al., 2008, 2009) reveals a new macro-environmental regulation of hair stem cell activity. Hair patterns, as well as most spatial patterns observed in nature, are established during development. However, the pigmented pattern on fish scales can accommodate to growth and regeneration, forming living Turing wave (Kondo et al., 2009). These investigators also show how some unexpected genes are involved in this patterning process.

Rubenstein et al. (2009) have developed a model for regeneration based on the 'regenerative' patterning of robots, including "nanobots". The authors argue that, in many ways, the organization of a population of homogeneous stem cells into distinct organogenesis units is similar to the need to organize a population of swarming robots. When a group of robots carry out a certain task, they can be subject to damage. Under that circumstance, how do they regroup or "regenerate» their original configuration so the remaining robots can continue to function, even at reduced capacity? This shows us one more example on how knowledge of pattern formation, stem cell patterning, tissue engineering and robotics can benefit one other.

\section{Conclusion}

By assembling these articles from different disciplines, we hope that this Special Issue of the Int. J. Dev. Biol. will work as a "virtual symposium", to catalyze future interactions among authors and readers from a wide range of backgrounds and disciplines. We have surveyed the research landscape of pattern formation in the multi-dimensional space of development, evolution and regeneration. The result is a sample of research programs on pattern formation today. We do not claim to have presented all the answers, or even all the questions, but we believe this collection of papers will help to catalyze and enhance our understanding of biological pattern formation, and how it may be applied in new fields. We are looking forward to a greater understanding of this fundamental and fascinating set of processes.

\section{Acknowledgements}

We would like to thank Dr. Arechaga, Editor-in-Chief of this journal, for offering us the opportunity to edit this Special Issue on pattern formation. We also like to thank all authors for their contributions. We are grateful to the busy scientists who gave up their time to be interviewed; those who helped the review process; and colleagues who gave advices on topics and authors. Chuong acknowledges the support of grants from NIAMS and NIA. Richardson acknowledges support from the Smart Mix programme of the Dutch Ministry for Economic Affairs and the Netherlands Scientific Organisation (NWO).

\section{References}

ABZHANOV, A., PROTAS, M., GRANT, B. R., GRANT, P. R., AND TABIN, C. J. (2004). Bmp4 and morphological variation of beaks in Darwin's finches. Science 305: $1462-1465$.

BALL, P. (1999). The self-made tapestry: pattern formation in nature. Oxford University Press, New York.

BAKER, SCHNELL, MAINI, P.K. (2009). Waves and patterning in developmental biology: vertebrate segmentation and feather bud formation as case studies. Int. J. Dev. Biol. 53: 783-794. (doi: 10.1387/ijdb.072493rb).

BRITTIJN S.A., DUIVESTEIJN S.J., BITTER W., DE BRUIN J.D., CHAMPAGNE D., CUPPENE., FLIK G., JANSSEN R., DE JONG I.M., ET AL. (2009). Zebrafish developmental patterning: new tools for medical research. Int. J. Dev. Biol. 53: 835-850. (doi: 10.1387/ijdb.082615sb)

BROCKES, J. P. AND KUMAR, A. (2005). Appendage regeneration in adult vertebrates and implications for regenerative medicine. Science 310: 19191923.

CHANG, C., WU, P., BAKER, R.E., MAINI, P.K., ALIBARDI, L., CHUONG, C.-M (2009). Reptile scale paradigm: Evo-Devo, pattern formation and regeneration. Int. J. Dev. Biol. 53: 813-826. (doi: 10.1387/ijdb.072556cc)

CHEN, J.Y. (2009). The sudden appearance of diverse animal body plans during the Cambrian explosion. Int. J. Dev. Biol. 53: 733-751. (doi: 10.1387/ ijdb.072513cj)

CHRISTLEY, S., ALBER, M.S, NEWMAN, S.A. (2007). Patterns of mesenchymal condensation in a multiscale, discrete stochastic model. PLOS Comput Biol. 3: e76.

CRICK F. (1970). Diffusion in embryogenesis. Nature 225: 420-422.

CHUONG, C-M., WU, P., PLIKUS MV, JIANG, TX, WIDELITZ, RB. (2006). Engineering Stem cells into organs: Topobiological transformations demonstrated by beak, feather and other ectodermal organ morphogenesis. Curr. Top. Dev. Biol. 72: 237-274.

CHUONG C.M. (2009a). Limb pattern, physical mechanisms and morphological evolution - an interview with Stuart A. Newman Int. J. Dev. Biol. 53: 663-671. (doi: $10.1387 / \mathrm{ijdb} .072553 \mathrm{cc}$ )

CHUONG C.M. (2009b). Skin, cornea and stem cells - an interview with Danielle Dhouailly Int. J. Dev. Biol. 53: 775-782. (doi: 10.1387/ijdb.072552cc)

DAVIDSON, E.H. AND ERWIN D.H. (2006). Gene regulatory networks and the evolution of animal body plans. Science 311: 796-800.

DEQUANT ML, GLYNN E, GAUDENZ K, WAHL M, CHEN J, MUSHEGIAN A POURQUI O. (2006). A complex oscillating network of signaling genes underlies the mouse segmentation clock. Science. 314: 1595-1598.

DUBOULR D. (1994). Temporal colinearity and the phylotypic progression: a basis for the stability of a vertebrate Bauplan and the evolution of morphologies through heterochrony. Dev.Supp/, 135-142.

EDELMAN, G.M. (1993). Topobiology: An Introduction to Molecular Embryology (Paperback) Basic Books.

HAZEN, R.M. (2009). The emergence of patterning in life's origin and evolution. Int J. Dev. Biol. 53: 683-692. (doi: 10.1387/ijdb.092936rh)

JIANG, T-X., WIDELITZ R.B, SHEN, W.M., WILL, P., WU, D.Y., LIN, C.M., JUNG, J.S., CHUONG, C.-M. (2004). Integument pattern formation involves genetic and epigenetic controls operated at different levels: Feather arrays simulated by a digital hormone model. Int. J. Dev. Biol. 48: 117-136.

KAUFFMAN, S.A. (1993). The Origins of Order: Self-Organization and Selection in Evolution. Oxford University Press, USA.

KONDO, S., IWASHITA, M.,YAMAGUCHI, M. (2009). How animals get their skin 
patterns: fish pigment patterns as a living Turing wave. Int. J. Dev. Biol. 53: 851856. (doi: $10.1387 / \mathrm{ijdb} .072505 \mathrm{sk})$

LIU, R.T., LIAW, S.S., MAINI, P.K. (2006). Two-stage Turing model for generating pigment patterns on the leopard and the jaguar. Phys. Rev. E. Stat. Nonlin. Soft Matter Phys. 74: 011914-8.

MAINI, P.K., BAKER, R.E., CHUONG, C.-M. (2006). The Turing model comes of molecular age. Science. 314: 1397-13.

MEINHARDT, H., GIERER, A. (2000). Pattern formation by local self-activation and lateral inhibition. Bioessays. 22: 753-760.

KMITA, M., KONCO, T. and DUBOULE, D. (2000). Targeted inversion of a polar silencer within the HoxD complex re-allocates domains of enhancer sharing. Nat. Genet. 26: 451-454.

KURAKU S and MEYER A, (2009). The evolution and maintenance of Hox gene clusters in vertebrates and the teleost-specific genome duplication. Int. J. Dev. Biol. 53: 765-773. (doi: 10.1387/ijdb.072533km)

MURRAY, J.D. (2003). Mathematical Biology II: Spatial Models and Biomedical Applications. New York: Springer-Verlag.

NEWMAN, S.A. AND BHAT, R. (2009). Dynamic patterning modules: a "pattern language" for development and evolution of multi-cellular from. Int. J. Dev. Biol. 53: 693-705. (doi: $10.1387 /$ ijdb.072481sn)

PETER, I.S. and DAVIDSON, E.H. (2009). Genomic control of patterning. Int. J. Dev. Biol. 53: 707-716. (doi: 10.1387/ijdb.072495ip)

PLIKUS M.V., MAYER J.A., DE LA CRUZ D., BAKER R.E., MAINI P.K., MAXSON R. AND CHUONG C.-M. (2008). Cyclic dermal BMP signaling regulates stem cell activation during hair regeneration. Nature. 451: 340-344.

PLIKUS, M.V., WIDELITZ, R.B., MAXON, R.E., CHUONG, C.-M. (2009). Analyses of regenerative wave patterns in adult hair follicle populations reveal macroenvironmental regulation of stem cell activity Int. J. Dev. Biol. 53: 857-868. (doi: $10.1387 /$ ijdb.072564mp)

RICHARDSON M.K. (2009a). Diffusible gradients are out - an interview with Lewis Wolpert. Int. J. Dev. Biol. 53: 659-662. (doi: 10.1387/ijdb.072559mr)

RICHARDSON M.K. (2009b). The Hox Complex - an interview with Denis Duboule Int. J. Dev. Biol. 53: 717-723. (doi: 10.1387/ijdb.072558mr)
RICHARDSON MK (2009c). Molecular tools, classic questions - an interview with Clifford Tabin. Int. J. Dev. Biol. 53: 725-731. (doi: 10.1387/ijdb.072575mr)

RICHARDSON MK and CHUONG, C.M. (2009). Regeneration and pattern formation - an interview with Susan Bryant. Int. J. Dev. Biol. 53: 827-833. (doi: $10.1387 /$ ijdb.082596mr)

ROIGNANT, J.Y. and TREISMAN, J.E. (2009). Pattern formation in the Drosophila eye disc Int. J. Dev. Biol. 53: 795-804. (doi: 10.1387/ijdb.072483jr)

RUBENSTEIN M, SAI Y, CHUONG, C.-M., SHEN WM. (2009). Regenerative patterning in swarm robots: mutual benefits of research in robotics and stem cell biology. Int. J. Dev. Biol. 53: 869-881. (doi: 10.1387/ijdb.092937mr)

SALAZAR-CIUDAD, I., JERNVALL J., NEWMAN, S.A. (2003). Mechanisms of pattern formation in development and evolution. Development 130: 2027-2037.

SLACK J. (1984). A Rosetta stone for pattern formation in animals? Nature 310 364-365.

STENN KS and PAUS R. Controls of hair follicle cycling. (2001). Physiol Rev. 81 449-494.

TOWERS M and TICKLE C (2009). Generation of pattern and form in the developing Limb Int. J. Dev. Biol. 53: 805-812. (doi: 10.1387/ijdb.072499mt)

TURING A. M. (1952). The Chemical Basis of Morphogenesis. Phil. Trans. Roy Soc. London Serie B-Biol. Sci. 237: 37-72.

VANAG, V.K and EPSTEIN, I.R. (2009). Pattern formation mechanisms in reactiondiffusion systems. Int. J. Dev. Biol. 53: 673-681. (doi: 10.1387/ijdb.072484vv)

WEISS, K.M. and BUCHANAN, A.V. (2009). The cooperative genome: organisms as social contracts. Int. J. Dev. Biol. 53: 753-763. (doi: 10.1387/ijdb.072497kw)

WOLPERT, L. (1969). Positional information and the spatial pattern of cell differentiation. J. Theor. Biol. 25: 1-47.

WOLPERT, L., SMITH, J., LAWRENCE, P., ROBERTSON, MEYEROWITZ, E. (2006). Principles of Development. Oxford University Press, Oxford.

WU, P., JIANG, T.-X., SUKSAWEANG, S, WIDELTZ, RB., CHUONG, CM., 2004. Molecular Shaping of the Beak. Science, 305: 1465-1466.

YUE, Z., JIANG, T.-X., WIDELITZ. R. B., AND CHUONG, CM. 2005. Mapping stem cell activities in the feather follicle. Nature 438: 1026-1029.
5 yr ISI Impact Factor $(2008)=3.271$

\section{For all the latest on Pattern Formation research, see our latest Special Issue edited by C.-M. Chuong and M.K. Richardson.}

http://www.ijdb.ehu.es/web/contents.php?vol=53\&issue=5-6

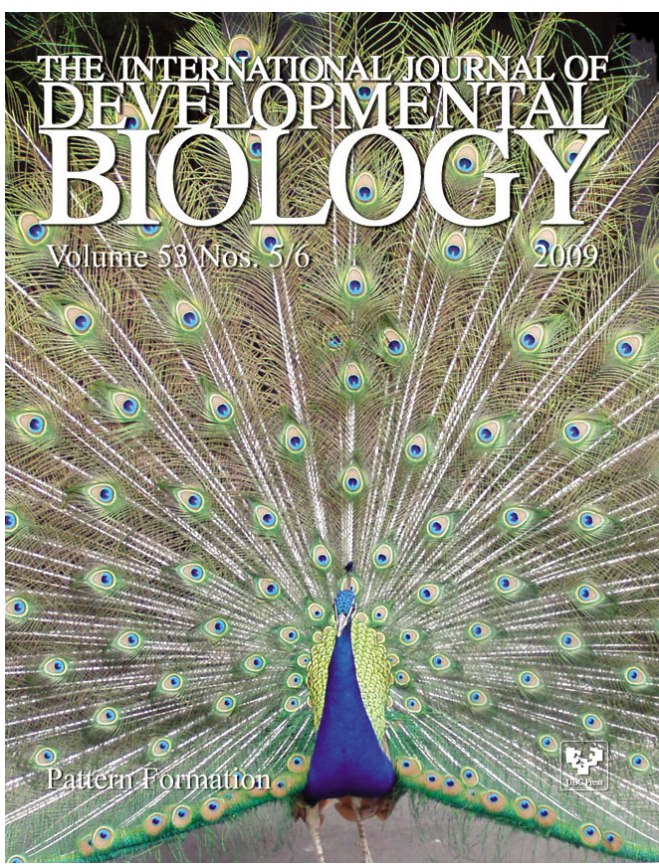




\section{Further Related Reading, published previously in the Int. J. Dev. Biol.}

See our recent Special Issue Fertilization, in honor of David L. Garbers and edited by Paul M. Wassarman and Victor D. Vacquier at: http://www.ijdb.ehu.es/web/contents. php?vol=52\&issue=5-6

Principles of branch formation and branch patterning in Hydrozoa

Stefan Berking

Int. J. Dev. Biol. (2006) 50: 123-134

Integument pattern formation involves genetic and epigenetic controls: feather arrays simulated by digital hormone models. Ting-Xin Jiang, Randall B Widelitz, Wei-Min Shen, Peter Will, Da-Yu Wu, Chih-Min Lin, Han-Sung Jung and Cheng-Ming Chuong Int. J. Dev. Biol. (2004) 48: 117-135

Patterning a multi-headed mutant in Hydractinia: enhancement of head formation and its phenotypic normalization.

Werner A Müller, Regina Teo and Frank Möhrlen

Int. J. Dev. Biol. (2004) 48: 9-15

Cell adhesiveness and affinity for limb pattern formation.

Hiroshi Yajima, Kenji Hara, Hiroyuki Ide and Koji Tamura

Int. J. Dev. Biol. (2002) 46: 897-904

Interactions between venation pattern formation genes in Arabidopsis thaliana

$\mathrm{H}$ Candela, A Martinez-Laborda, JL Micol

Int. J. Dev. Biol. (2001) 45: S35-S36

Morphological chimeras of larvae and adults in a hydrozoan--insights into the control of pattern formation and morphogenesis.

$M$ Kroiher

Int. J. Dev. Biol. (2000) 44: 861-866

Cell lineage analysis of pattern formation in the Tubifex embryo. II. Segmentation in the ectoderm.

A Nakamoto, A Arai and T Shimizu

Int. J. Dev. Biol. (2000) 44: 797-805

A cell type-specific effect of calcium on pattern formation and differentiation in dictyostelium discoideum.

R Baskar, P Chhabra, P Mascarenhas and V Nanjundiah

Int. J. Dev. Biol. (2000) 44: 491-498

Endochondral bone formation in toothless (osteopetrotic) rats: failures of chondrocyte patterning and type $X$ collagen expression.

S C Marks, C Lundmark, C Christersson, T Wurtz, P R Odgren, M F Seifert, C A Mackay, A Mason-Savas and S N Popoff

Int. J. Dev. Biol. (2000) 44: 309-316

Limb development: an international model for vertebrate pattern formation.

C Tickle

Int. J. Dev. Biol. (2000) 44: 101-108

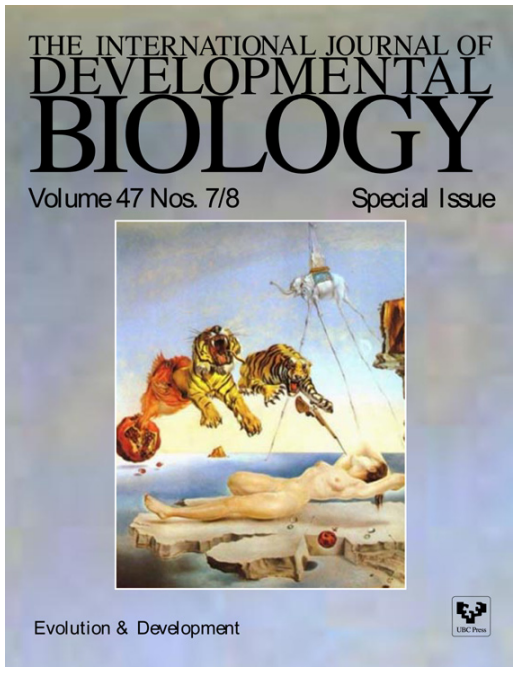

5 yr ISI Impact Factor $(2008)=3.271$

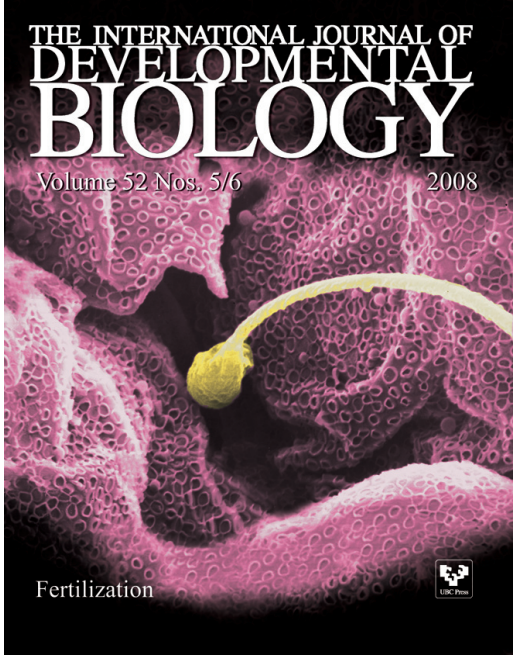

